\title{
Controlling Relative Humidity in Modified Atmosphere Packages of Tomato Fruit
}

\author{
Ahmad Shirazi and Arthur C. Cameron \\ Department of Horticulture, Michigan State University, East Lansing, \\ MI 48824
}

\begin{abstract}
Additional index words. Lycopersicon esculentum, modified-humidity packaging
\end{abstract}
Abstract. The feasibility of controlling relative humidity in modified atmosphere packages using compounds possessing Type III sorption isotherm behavior was studied. Ten grams each of dry sorbitol, xylitol, $\mathrm{NaCl}, \mathrm{KCl}$, or $\mathrm{CaCl}_{2}$ sealed with one maturegreen tomato (Lycopersicon esculentum L.) fruit at $20 \mathrm{C}$ in simulated packages for 48 days resulted in stable relative humidities of $\approx 75 \%, 80 \%, 75 \%, 85 \%$, and $35 \%$, respectively. Relative humidity was a function of the ratio of chemical to fruit mass. Relative humidities within control packages were in the range of $96 \%$ to $100 \%$ throughout the experiments. A simple system that uses spunbonded polyethylene pouches for the application of this humidity control method to packages is described. The storage life of packaged red-ripe tomato fruit at $20 \mathrm{C}$ was extended from 5 days using no pouch to 15 to 17 days with a pouch containing $\mathrm{NaCl}$, mainly by retardation of surface mold development.

Modified atmosphere packaging (MAP) has been used as a supplement or even a substitute for refrigeration to prolong the storage life of fresh produce during transport and retail handling (Kader et al., 1989). Recently, improved models and techniques have been developed for prediction and control of $\mathrm{O}_{2}$ levels in MAP systems for tomatoes (Cameron, 1990; Cameron et al., 1989). However, even when packages constructed from low-density polyethylene (LDPE) were designed to give optimal $\mathrm{O}_{2}$ and $\mathrm{CO}_{2}$ concentrations, the shelf life was not equal to that obtained under controlled-atmosphere conditions. For instance, red-ripe tomatoes held in a flow-through system at $2 \% 0_{2}$ remained in salable condition for 40 days at 20C compared to 15 days in a package optimized to the same $\mathrm{O}_{2}$ concentration (Boylan-Pett, 1986). The limiting factor in the package was the appearance of molds that were associated with high in-package relative humidity (RI-I), but were not observed in the flow system. Several other researchers have noted condensation and/or mold and bacterial development in MAP systems (Grierson, 1969; Hardenburg, 1951; Scott et al., 1964).

Most of the major pathogens affecting the postharvest life of tomato fruit need an environment with a water activity of more than 0.80 for their growth (Troller and Christian, 1978). Reduction of humidity to levels below the critical water activity of microorganisms should be an effective way to limit

Received for publication 17 July 1991. Accepted for publication 15 Aug. 1991. We acknowledge the Michigan Agricultural Experiment Station for its support of this research. The cost of publishing this paper was defrayed in part by the payment of page charges. Under postal regulations, this paper therefore must be hereby marked advertisement solely to indicate this fact. their growth. The generally recommended levels of $85 \%$ to $95 \%$ RH (Hardenburg et al., 1986) for storage of fresh produce represent a compromise to prevent excessive weight loss while providing some control of microbial spoilage.

Perforation of bags has been used to reduce in-package RH (Hardenburg, 1954; Kaufman et al., 1956) although perforations large enough to affect in-package RH preclude the possibility of modified-atmosphere conditions within the package. In-package RH can be reduced by using films with a high water vapor transmission rate but cannot be controlled to specific levels using this approach alone, since in-package $\mathrm{RH}$ is also a function of RH in the surrounding environment, which can change markedly during handling and storage (Saguy and Mannheim, 1975). Desiccants such as $\mathrm{CaC1}_{2}$ have been used to lower in-package RH (Bedrosian and Schiffman, 1983; Eaves, 1960; Scott et al., 1964).

The moisture content of any material approaches an equilibrium level after exposure to a given $\mathrm{RH}$ by gaining or losing water. Establishment of equilibrium, however, may take days or even weeks, depending on the system (Labuza, 1984). Compounds, such as sorbitol, xylitol, and $\mathrm{NaCl}$, that exhibit Type III sorption isotherm behavior as defined by Brunauer (1945), absorb relatively little moisture until RH increases to some critical level (Kaufmann, 1960; Labuza, 1984; Xyrofin, 1985). As the RH is increased above this point, these compounds absorb increasingly more water. At higher RH levels, such compounds can absorb several times their own dry weights in water. This behavior is the basis for RH control by saturated salt solutions that has long been used in experiments (Winston and Bates, 1960 Young, 1967).

The ability to create a stable predetermined RH in sealed packages with the po- tential for reducing decay problems and without causing shriveling would be valuable for improving the success of MAP systems. Currently, no reliable method for controlled reduction has been reported. The primary purpose of this study was to determine the feasibility of using predried crystals of compounds possessing Type III sorption isotherm behavior for control of RH within fresh-produce packages. In addition, we show how the concept can be simply and efficiently adapted for a MAP system to reduce mold and extend shelf life of tomato fruit.

For simulated package experiments, 'Duke' tomato fruit were harvested mature-green from the Plant Science greenhouses, Michigan State Univ., or red-ripe fruit were purchased from a local market. For the MAP experiment, 'Summer Flavor 6000' fruit were received at the breaker stage and ripened at $20 \mathrm{C}$ to redripe. In all cases, fruit of uniform size and free of visible defects were held in unsealed polyethylene bags at $20 \mathrm{C}$ for a minimum of $24 \mathrm{~h}$ to reach temperature equilibrium before the start of the experiments. Each fruit was weighed before an experiment was started. In the first experiment, fruit weighed 70 to $90 \mathrm{~g}$; in the second experiment, fruit weight ranged from 130 to $160 \mathrm{~g}$.

Each experimental chamber had a solid base, a top, and a cylindrical body of 6.4mm-thick polyacrylic plastic $(8.3 \mathrm{~cm}$ height, $10.2 \mathrm{~cm}$ id.). A hole of $10.2 \mathrm{~cm}$ id. was cut in the top for film insertion, and two holes of $6.4 \mathrm{~mm}$ id. were cut in the cylinder wall for probe access and headspace gas sampling. A piece of 0.051 -mm-thick (2-roil) LDPE film (LDF-301, Dow Chemical, Midland, Mich.) was held in place at the top of the chamber by two rubber gaskets. The film's permeability at 20C was 102 and 486 $\mathrm{cm}^{3} \cdot \mathrm{mm} / \mathrm{m}^{2}$ per day per atm for $\mathrm{O}_{2}$ and $\mathrm{CO}_{2}$, respectively. Water vapor transmission rate of the film was $0.81 \mathrm{~g} \cdot \mathrm{m}^{-2} \cdot \mathrm{day}^{-1}$ (a perme-

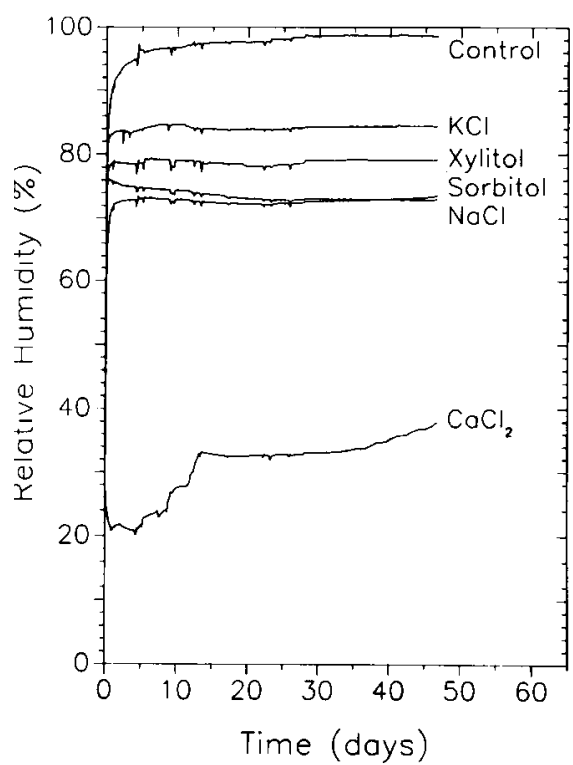

Fig. 1. In-package relative humidity for 48 days at $20 \mathrm{C}$ using one mature-green 'Duke' tomato fruit with $10 \mathrm{~g}$ sorbitol, xylitol, $\mathrm{NaCl}, \mathrm{KCl}$, or $\mathrm{CaCl}_{2}$, or no sorbent (control). 

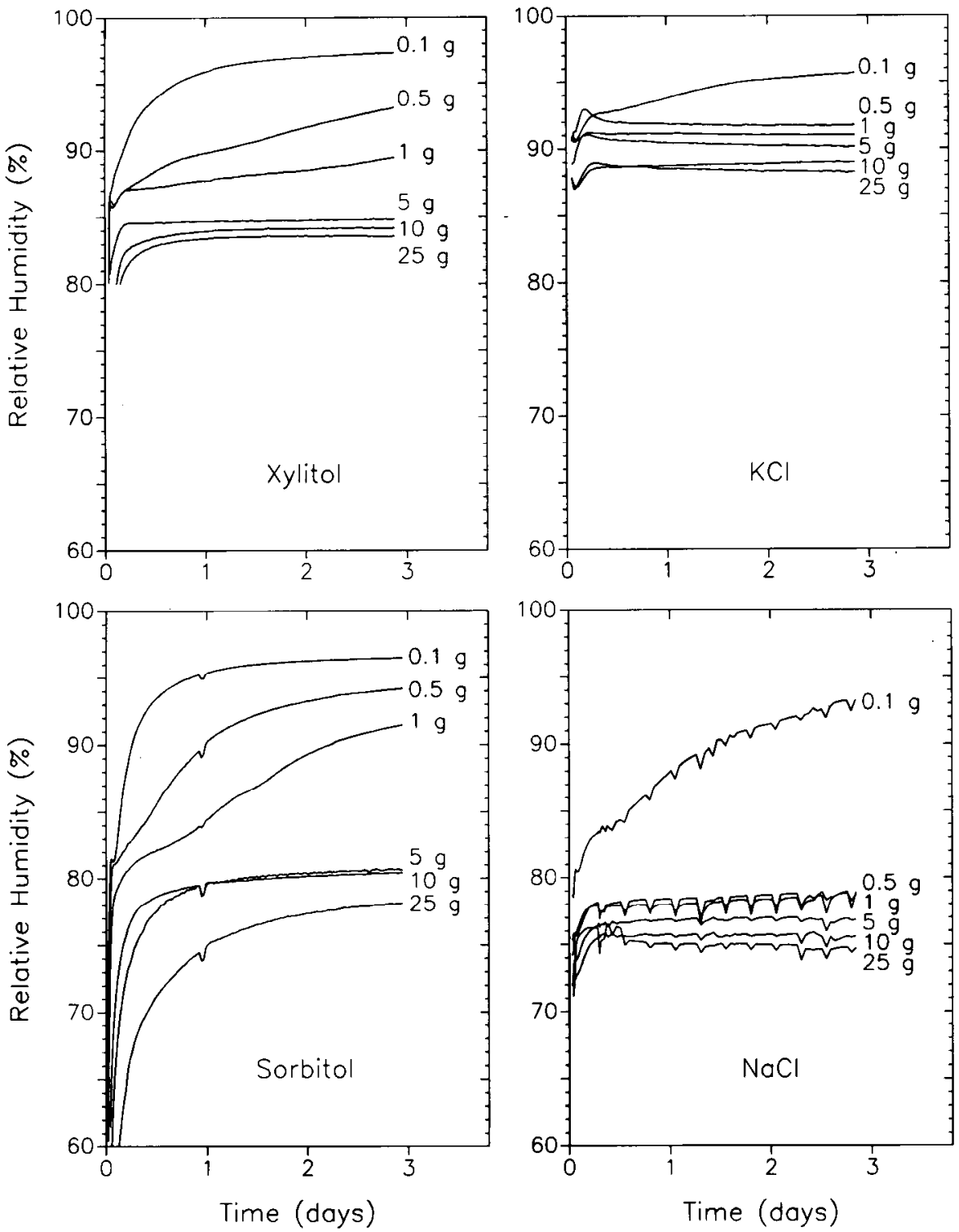

Fig. 2. In-package relative humidity for 3 days at 20C using one red 'Duke' tomato fruit with 0.1, $0.5,10.0$, or $25.0 \mathrm{~g}$ xylitol, sorbitol, $\mathrm{KCl}$, or $\mathrm{NaCl}$.

ability coefficient of $20,000 \mathrm{~cm} \cdot \mathrm{mm} / \mathrm{m}^{2}$ per day per atm) as measured at $20 \mathrm{C}$ and $50 \%$ $\mathrm{RH}$.

All chemicals were dried at $75 \mathrm{C}$ for $48 \mathrm{~h}$ before use; $\mathrm{NaCl}$ and $\mathrm{KCl}$ were analytical grade (Mallinckrodt Chemical Works, Paris, $\mathrm{Ky}$.), $\mathrm{CaCl}_{2}$ was desiccant grade (Mallinckrodt Chemical Works), D-sorbitol was anhydrous (Sigma Chemical Co., St. Louis), and xylitol was crystalline with a mean crystal size of $0.57 \mathrm{~mm}$ (Xyrofin, Basel, Switzerland). Chemicals were spread evenly in a $100 \times 15-\mathrm{mm}$ petri dish base around a 60 $\times 15-\mathrm{mm}$ dish at the center (covering an area of $\left.\approx 50 \mathrm{~cm}^{2}\right)$. A combined temperature and humidity probe (Model 850; General Eastern, Watertown, Mass.) was inserted through a septum and positioned above the fruit before the container was sealed. The probe was precalibrated by the manufacturer and had a sensitivity of $0.1 \% \mathrm{RH}$, repeatability of $0.5 \%$, and accuracies of $\pm 2 \%$ within $15 \%$ to $99 \% \mathrm{RH}$ at $25 \mathrm{C}$ and $\pm 0.5 \mathrm{C}$ within 5 to $50 \mathrm{C}$ according to specifications. The performance of the probe was checked against known humidities before each experiment.

Temperature and humidity values were collected at regular intervals with a datalogger (Model no. 516B-32; Omnidata International, Logan, Utah) (Shirazi, 1989). All experiments were conducted at $20 \mathrm{C}$ and repeated with similar results unless otherwise noted.

Headspace was sampled using 1-ml plastic syringes at least two times after equilibrium was established. Oxygen and $\mathrm{CO}_{2}$ concentrations were determined with an $\mathrm{O}_{2}$ analyzer (Model S-3A/II; Ametek, Pittsburgh) and an infrared gas analyzer (Type 225 MK3; ADC, Haddesdon, England) connected in series to a strip chart recorder (Model 1200; Linear Instruments Corp., Reno, Nev.). Nitrogen was used as the carrier gas at $200 \mathrm{ml} \cdot \mathrm{min}^{-1}$

The possibility of using a water source other than fresh produce was investigated to minimize variation. Rates of weight (water) loss from red tomatoes and from containers of deionized water were monitored for 2 days in a controlled environment room set at $20 \mathrm{C}$ and $35 \%$ RH, using an analytical balance
(AE 163; Mettler, Hightstown, N.J.). The average rates of weight (mostly water) loss from red tomatoes within the 110- to $140-\mathrm{g}$ range and evaporation from $50-\mathrm{ml}$ beakers containing $30 \mathrm{ml}$ deionized water were 0.0418 $\mathrm{g} \cdot \mathrm{h}^{-1}(\mathrm{SD}=0.0066, \mathrm{n}=3)$ and 0.0416 $\mathrm{g} \cdot \mathrm{h}^{-1}(\mathrm{SD}=0.0013, \mathrm{n}=3)$, respectively.

A shelf life experiment was conducted at $20 \mathrm{C}$ using two red-ripe tomato fruits $(\approx 450$ g) per sealed LDPE film package $(4.4 \times$ $10-3 \mathrm{~cm}$ thick, $600 \mathrm{~cm}^{2}$ surface area, permeability for $\mathrm{O}_{2}$ and $\mathrm{CO}_{2}$ of 125 and $567 \mathrm{~cm}^{3}$ (STP) $\mathrm{mm} / \mathrm{m}^{2}$ per day per atm, respectively). One-half of the packages contained a pouch constructed of spunbonded polyethylene (9 $\times 2 \times 15 \mathrm{~cm}$; Tyvek type 1059B, Dupont, Wilmington, Del.) in which was sealed 20 $\mathrm{g}$ of dry crystalline $\mathrm{NaCl}$. The pouch was heat-sealed through the middle such that each half contained $\approx 10 \mathrm{~g}$ of the compound. Eight perforations were made in half the sealed LDPE packages using a 26-gauge needle $(\approx 0.5$-mm-diameter, two holes per comer $)$ to compare the effects of nearly ambient vs. low O2. Gas samples were withdrawn by means of 1-ml plastic syringes through a dap of silicone (no. 280; General Electric Co., Waterford, N.Y.) cured on a small piece of PVC electrical tape placed on each package (Boylan-Pett, 1986). Oxygen and $\mathrm{CO}_{2}$ concentrations in the packages were measured 3,6 , and 12 days after the initiation of the experiment. Visual evaluations were performed daily, and the shelf life of each fruit was defined as the time until the first signs of fungal growth or of a disorder appeared. A two-way factorial arrangement of treatments (humidity and $\mathrm{O}_{2}$ control) in a randomized complete block design was used for the experiment with 18 observations per treatment. Shelf life data were subjected to analysis of variance (ANOVA). Average concentrations of $\mathrm{O}_{2}$ and $\mathrm{CO}_{2}$ were calculated from the gas analysis data.

$\mathrm{RH}$ in control packages reached $98 \%$ and remained at that level for the duration of the experiment (Fig. 1). Ten grams of xylitol, $\mathrm{KCl}, \mathrm{NaCl}$, or sorbitol held $\mathrm{RH}$ at $78 \%$ to $79 \%, 84 \%$ to $85 \%, 73 \%$ to $76 \%$, and $72 \%$ to $74 \%$ for 48 days, respectively, in packages with a single tomato fruit (70-90 g). The $\mathrm{RH}$ values over $\mathrm{NaCl}$ and $\mathrm{KCl}$ were very similar to ERH values over their saturated solutions, which are $75 \%$ and $85 \%$, respectively (Weast, 1984). The in-package RH over xylitol, however, was $\approx 6 \%$ lower than the published RH over a saturated solution (Xyrofin, 1985). The in-package RH over $10 \mathrm{~g}$ $\mathrm{CaCl}_{2}$ with one 150 -g tomato fruit was between $30 \%$ to $35 \%$.

The amount of each compound used affected the respective in-package $\mathrm{RH}$. In the case of sorbitol, very little reduction of inpackage RH took place when 0.1 g/fruit (130 to $160 \mathrm{~g}$ ) was used (Fig. 2). Sorbitol at $1 \mathrm{~g}$ reduced in-package $\mathrm{RH}$ to $80 \%$ initially but apparently became saturated with time since RH slowly increased over 3 days to $\approx 90 \%$. Five and $10 \mathrm{~g}$ both produced similar in-package $\mathrm{RH}$ of $\approx 80 \%$. Sorbitol at $25 \mathrm{~g}$ produced a slightly lower in-package RH value initially but equilibrated at about a $2 \%$ lower 


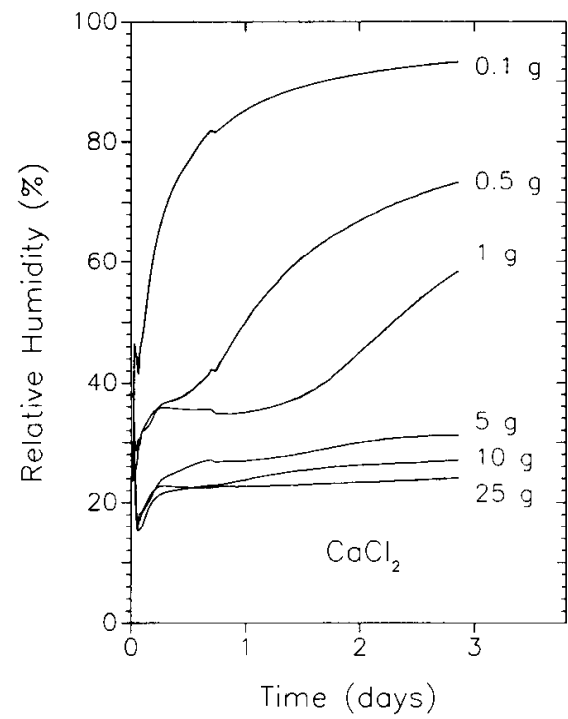

Fig. 3. In-package relative humidity for 3 days at $20 \mathrm{C}$ using one red 'Duke' tomato fruit with $0.1,0.5,10.0$, or $25.0 \mathrm{~g} \mathrm{CaCl}_{2}$.

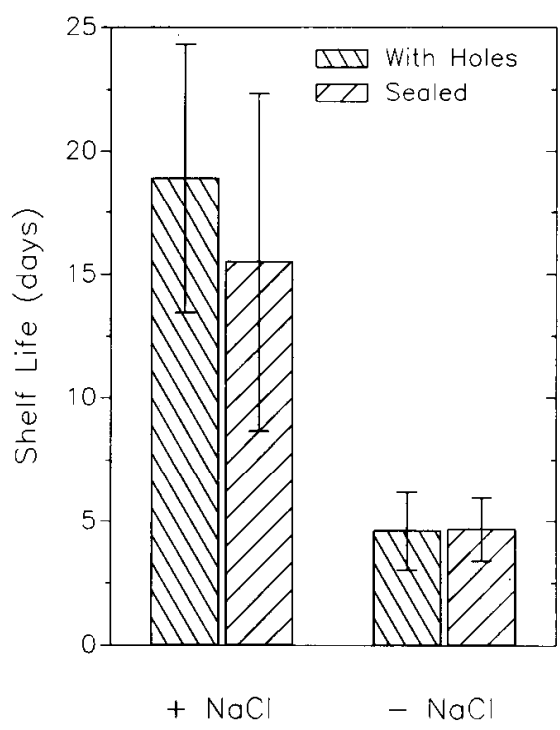

Fig. 4. Effects of controlled humidity on storage life of red-ripe 'Summer Flavor 6000' tomato fruit in modified atmosphere packages. Each bar represents mean shelf life for 18 fruit \pm SD. Dry $\mathrm{NaCl}(10 \mathrm{~g} / 225 \mathrm{~g}$ fruit) packed in spunbonded polyethylene was used to control inpackage relative humidity at $\approx 80 \%$. Average $\mathrm{O}_{2}$ and $\mathrm{CO}_{2}$ were $\approx 3 \%$ and $6 \%$ in sealed packages and $17 \%$ and $4 \%$ in packages with holes.

RH on the 3rd day than did 5 or $10 \mathrm{~g}$. Xylitol showed a similar pattern as sorbitol (Fig. 2). In this case, $1 \mathrm{~g}$ produced a relatively stable in-package $\mathrm{RH}$ over 3 days. The in-package $\mathrm{RH}$ values corresponding to 5,10 , and $25 \mathrm{~g}$ xylitol were generally similar and $\approx 84 \%$ to $88 \%$. One, 5,10 , and $25 \mathrm{~g}$ of $\mathrm{KCl}$ produced $\approx 90 \%$ RH (Fig. 2). With $0.1 \mathrm{~g}$, no stable $\mathrm{RH}$ was obtained. RH values generated when 0.5 to $25 \mathrm{~g}$ of $\mathrm{NaCl}$ was used over 3 days were similar (Fig. 2). All of the stated levels held RH stable at $=75 \%$. No stable RH was obtained when $0.1 \mathrm{~g} \mathrm{NaCl}$ was used. In experiments with $\mathrm{CaCl}_{2}, 5,10$, and $25 \mathrm{~g}$ generated similar RH values (20\% to $30 \%$ ) (Fig.
3). When $1 \mathrm{~g}$ of $\mathrm{CaCl}_{2}$ was used, $\mathrm{RH}$ stabilized at $\approx 35 \%$ for nearly 1 day and then increased. A similar pattern was observed with $0.5 \mathrm{~g}$ of $\mathrm{CaCl}_{2}$, although the duration of stable RH was only for about one-third of a day.

Bedrosian and Schiffman (1983) claim that $\mathrm{CaCl}_{2}$ can be used to control in-package $\mathrm{RH}$ and that the "amount of desiccant used is not critical" as long as enough of the compound is used so that it remains active during the storage period. Our studies, however, show that in-package $\mathrm{RH}$ depends on the amount of $\mathrm{CaCl}_{2}$ per fruit. For example, when $0.5 \mathrm{~g} \mathrm{CaCl}_{2}$ was used with a 130 - to $160-\mathrm{g}$ fruit, in-package $\mathrm{RH}$ was in the range of $60 \%$ after $\approx 2$ days. Tomatoes packaged with 10 $\mathrm{g} \mathrm{CaCl}_{2}$ lost $16 \%$ of their fresh weight over 48 days of storage and shriveled severely. No shriveling was observed in fruits in these experiments as long as weight loss was $\leq 7 \%$ (data not shown). It maybe possible to optimize the quantity of $\mathrm{CaCl}_{2}$ added to the package such that it removes surface moisture during early stages but then becomes saturated.

In general, measured RH values were similar from one experiment to the next, although some variability was noted. Any external factor, such as cultivar or growing condition, that affects the resistance of the fruit skin to water loss may contribute to variation. Accuracy and precision of the humidity sensors may account for some discrepancies observed in the measured inpackage RH values, although accuracy of the units was found to conform to the specifications when tested against an electric psychrometer $( \pm 2 \% \mathrm{RH}$ at $25 \mathrm{C}, 20 \%$ to $85 \%$ $\mathrm{RH})$.

The average storage life of red-ripe tomato fruit at $20 \mathrm{C}$ was increased from $\approx 5$ to 17 days when $\mathrm{NaCl}$ was included in the package (Fig. 4). The $\mathrm{NaCl}$ effect was statistically significant; however, there was no significant effect on shelf life of modifying $\mathrm{O}_{2}$ levels from $16 \%$ to $17 \%$ (i.e., with perforations) to $\approx 3 \%$ in the sealed packages. The corresponding $\mathrm{CO}_{2}$ levels in the sealed packages ranged from $4 \%$ to $6 \%$. The effect of humidity control on shelf life was highly significant ( $P=0.0001$ ). The experiment was repeated three times with similar results. In general, the limiting factor for shelf life was the appearance of molds on the stem scar. Fusarium sp. and Alternaria sp. were identified by the Diagnostic Clinic, Plant Biology Lab, Michigan State Univ., on several infected fruits. Botrytis sp. and Penicillium $\mathrm{sp}$. were noted in fewer cases.

In the trial application experiment, dry crystals of $\mathrm{NaCl}$ were enclosed in packets made of a food-grade, spunbonded polyethlene film. The small holes in these films readily permit the movement of water vapor, but completely block that of liquid water. Over extended periods, the salts became saturated with water. The solutions were held separate from the fruit by the spunbonded polyethylene and continued to maintain control of humidity. Spunbonded polyethylene is relatively inexpensive, and pouches con- taining salts or sugar alcohols could prove to be an affordable, effective system for commercial application. The actual amount of leakage of salt solutions through the film has been minimal under our conditions. The packets can be dried and reused as needed.

The technique of controlling in-package humidity described here is independent of outside RH, as opposed to using films with high water vapor transmission rates (Saguy and Mannheim, 1975). Ultimately, it may be useful to combine the two techniques since it might permit a reduction in the amount of compound that needs to be included in the package. Although this concept is similar to the use of saturated salt solutions, it is important to note that this system never comes to equilibrium, but is at steady state. The ability to control RH thus is based on the rate of water absorption by the compounds relative to the rate of transpiration by the fruit. In these experiments, 5 to $10 \mathrm{~g}$ of chemical per fruit of 130 to $160 \mathrm{~g}$ was required to maintain a stable RH. Less compound was often unable to absorb water quickly enough to control humidity. The amount of compound per fruit most likely could be reduced if improved methods for dispersion were used to maximize the surface area for absorption.

\section{Literature Cited}

Bedrosian, K. and R.F. Schiffman. 1983. Controlled atmosphere produce. U.S. Patent 4423080 .

Boylan-Pett, W. 1986. Design and function of a modified atmosphere package for tomato fruit. MS Thesis, Michigan State Univ., East Lansing.

Brunauer, S. 1945. The adsorption of gases and vapors. L Physical adsorption. Princeton Univ. Press, Princeton, N.J.

Cameron, A.C. 1990. Modified atmosphere packaging: A novel approach for optimizing package oxygen and carbon dioxide. Proc. 5th Intl. Controlled Atmosphere Conf. 14-16 June 1989, Wenatchee, Wash.

Cameron, A. C., W. Boylan-Pett, and J. Lee. 1989. Design of modified atmosphere packaging systems: Modeling oxygen concentrations within sealed packages of tomato fruits. J. Food. Sci. 54:1413-1415.

Eaves, C.A. 1960. A modified-atmosphere system for packages of stored fruit. J. Hort. Sci. 35(2) :110-117.

Grierson, W. 1969. Consumer packaging of citrus fruits. Proceedings of 1st Intl. Citrus Symp. 3:1389-1401.

Hardenburg, R.E. 1951. Further studies on moisture losses of vegetables packaged in transparent films and their effect on shelf life. Proc. Amer. Soc. Hort. Sci. 57:277-284.

Hardenburg, R.E. 1954. How to ventilate packaged produce. Pre-Pack-Age 7(6):14-17.

Hardenburg, R. E., A.E. Watada, and C.Y. Wang. 1986. The commercial storage of fruits, vegetables, and florist and nursery stocks. U.S. Dept. of Agr. Hdbk. 66.

Kader, A. A., D. Zagory, and E. Kerbel. 1989. Modified atmosphere packaging of fruits and vegetables. Critical Rev. in Food Sci. \& Nutr. 28(1):1-30.

Kaufman, J., R.E. Hardenburg, and J.M. Lutz. 1956. Weight loss and decay of Florida and California oranges in mesh and perforated poly- 
ethylene consumer bags. Proc. Amer. Soc. Hort. Sci. 67:244-250.

Kaufmann, D.W. 1960. Low temperature properties and uses of salt brine, p. 537-538. In: D.W. Kaufmann (ed.). Sodium chloride: The production and properties of salt brine. Amer. Chem. Soc. Monogr. Ser. Reinhold Publ., New York.

Labuza, T.P. 1984. Moisture sorption: Practical aspects of isotherm measurement and use. Amer. Assn. Certified Chem., St. Paul, Minn. p. 42. Saguy, I. and C.H. Mannheim. 1975. The effect of selected plastic films and chemical dips on the shelflife of Marmande tomatoes. J. Food Technol. 10:547-556.

Scott, K.J., E.G. Hall, E.A. Roberts, and R.B. Wills. 1964. Some effects of the composition of the storage atmosphere on the behavior of apples stored in polyethylene film bags. Austral. J. Expt. Agr. \& Animal Husbandry 4:253259.

Shirazi, A. 1989. Modified humidity packaging of fresh produce. PhD Diss., Michigan State Univ., East Lansing.

Troller, J.A. and J.H. Christian. 1978. Water activity and food, p. 87-92, 146-147, 157, 200,
215-216. Academic, New York.

Weast, R.C. (ed). 1984. CRC handbook of chemistry and physics, p. E-37, E-42. CRC Press, Boca Raton, Fla.

Winston, P.W. and D.H. Bates. 1960. Saturated solutions for the control of humidity in biological research. Ecology 41:232-237.

Xyrofin Ltd. 1985. Xylitol tablets, granulation and impression techniques. 2nd ed. Xyrofin, Ltd., Basel, Switzerland.

Young, J.F. 1967. Humidity control in the laboratory using salt solutions: A review. J. Applied Chem. 17:241-245. 